\title{
Educación y pedagogía: divergencia conceptual y convergencia en la dignidad de la persona ${ }^{1}$
}

Gustavo Adolfo Esparza Urzúa

\section{Introducción}

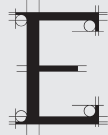

n este pequeño trabajo se tiene por objetivo reflexionar sobre las diferencias entre la Educación [Ed.] y la Pedagogía [Pe.] y el fin común en que ambas confluyen, según la teoría fenomenológico personalista de Karol Wojtyła (1982). La hipótesis general que propongo es que, a pesar de las diferencias conceptuales, ambas prácticas, según la teoría del filósofo polaco, tienen como tarea central la dignificación de la persona. En parte, el trabajo recupera una serie de resultados previos en donde se realizó un análisis crítico de las tareas de ambos conceptos y donde se concluyó que ambas deben fomentar la dignidad humana (cfr. Esparza, 2007). Otro interés secundario para el desarrollo de este trabajo es profundizar en los fundamentos metodológicos con los que algunos centros educativos buscan la afirmación de la persona por sí misma.

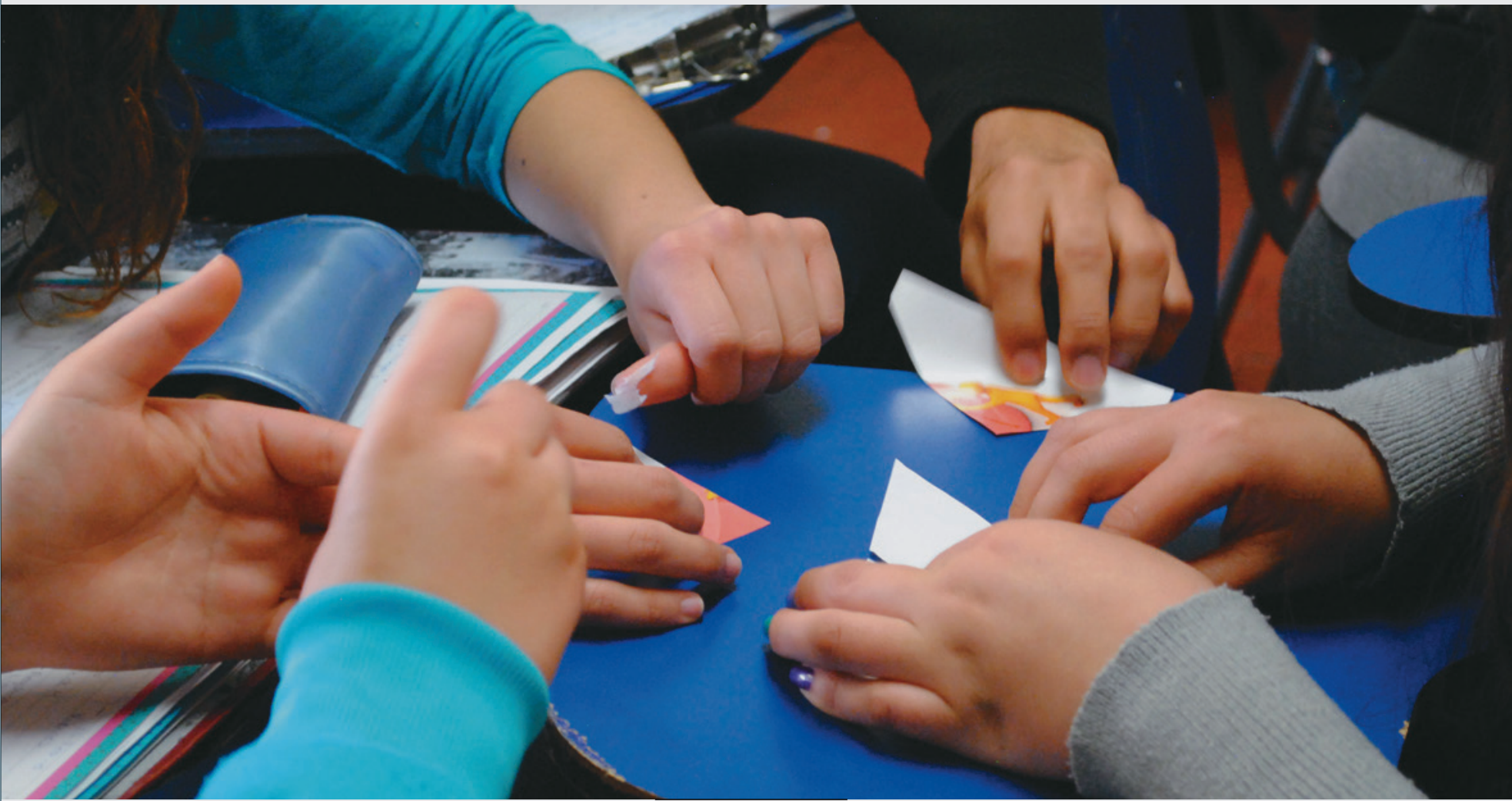

1 Agradezco los comentarios y sugerencias del comité evaluador de la revista y del profesor Enrique Berrueta para la mejora del texto. 


\section{Divergencias: fundamentos personalistas para distinguir entre Educación y Pedagogía}

Un fundamento básico de la filosofía personalista de Karol Wojtyła (1982: 23 y ss.) es que, así como la operación sigue al ser, una inversión de los términos permite sostener que el ser sigue a la acción. En términos generales, este desarrollo metodológico conlleva a, entre otros, los siguientes resultados: 1) la acción revela a la persona; 2) toda acción permite la orientación de una acción hacia fines específicos; 3 ) los agentes educativos son los encargados de organizar y sistematizar las acciones de otros individuos para que éstos logren ciertos fines esperados y así desarrollarse como seres humanos integrales (cfr. Esparza, 2007: 133-142).

Para Karol Wojtyła (1982), el análisis de la acción permite la construcción de un "proceso cognoscitivo" que tiene su origen en la "experiencia del hombre", la cual es "continua" (p. 3) a pesar de las intermitencias cognitivas -por ejemplo, cuando el individuo duerme-. Con esto, el filósofo polaco plantea que todas las acciones se revelan como acciones desarrolladas por la misma persona en el marco de un análisis fenomenológico (Wojtyła, 1982: caps. 1 y 2). Este mismo análisis, según el autor, es el que revela a la persona misma como un ser actuante y sujeto de experiencias.

A lo largo de su obra Persona y acción, el polaco deja en claro que existe una diferencia metodológica entre la acción propiamente dicha y su análisis. Se puede decir que el momento denominado como "algo ocurre en el hombre" corresponde a la acción educativa, ya que el conjunto de acciones confluyen en el individuo sin necesariamente existir un momento de conciencia reflexiva, aunque sí un cambio de conducta, mientras que la promoción de las acciones que encaminan a que el "ser humano actúe" dependen, en gran medida, de una capacidad de organización y de intencionalidad tanto del agente educativo como de los propios individuos en tanto que educandos (Wojtyła, 1982: 33 y ss; Esparza, 2007: cap. 2).

Como se ha mostrado en otro trabajo ( $c f r$. Esparza, 2007), este marco filosófico permite sostener una diferencia importante entre $E d$ y $P e$ : la primera se identifica con el conjunto de acciones desarrolladas por un individuo y que le permiten actuar de acuerdo a un entorno; la segunda con la promoción y construcción de las acciones que favorecerán el desarrollo de un ser humano.

En concreto, la perspectiva personalista de Wojtyła propone distinguir entre, por un lado, el conjunto de acciones con las que un individuo logra adaptarse a un entorno cultural (educación) y, por el otro, las acciones que un agente promueve para que el individuo experimente, actúe y alcance ciertos ideales esperados (pedagogía). Parecería que a toda acción correspondería un acto pedagógico y viceversa, pero a quienes se han dedicado a la labor educativa les resultará claro que no toda organización de actividades que busca el cambio de conducta, necesariamente, se traduce en una acción educativa; en algunos casos se convierte en un acto de supresión, negación o enajenación de la persona; de allí que sea tan necesario distinguir entre una modificación de la conducta, Educación y Pedagogía. 


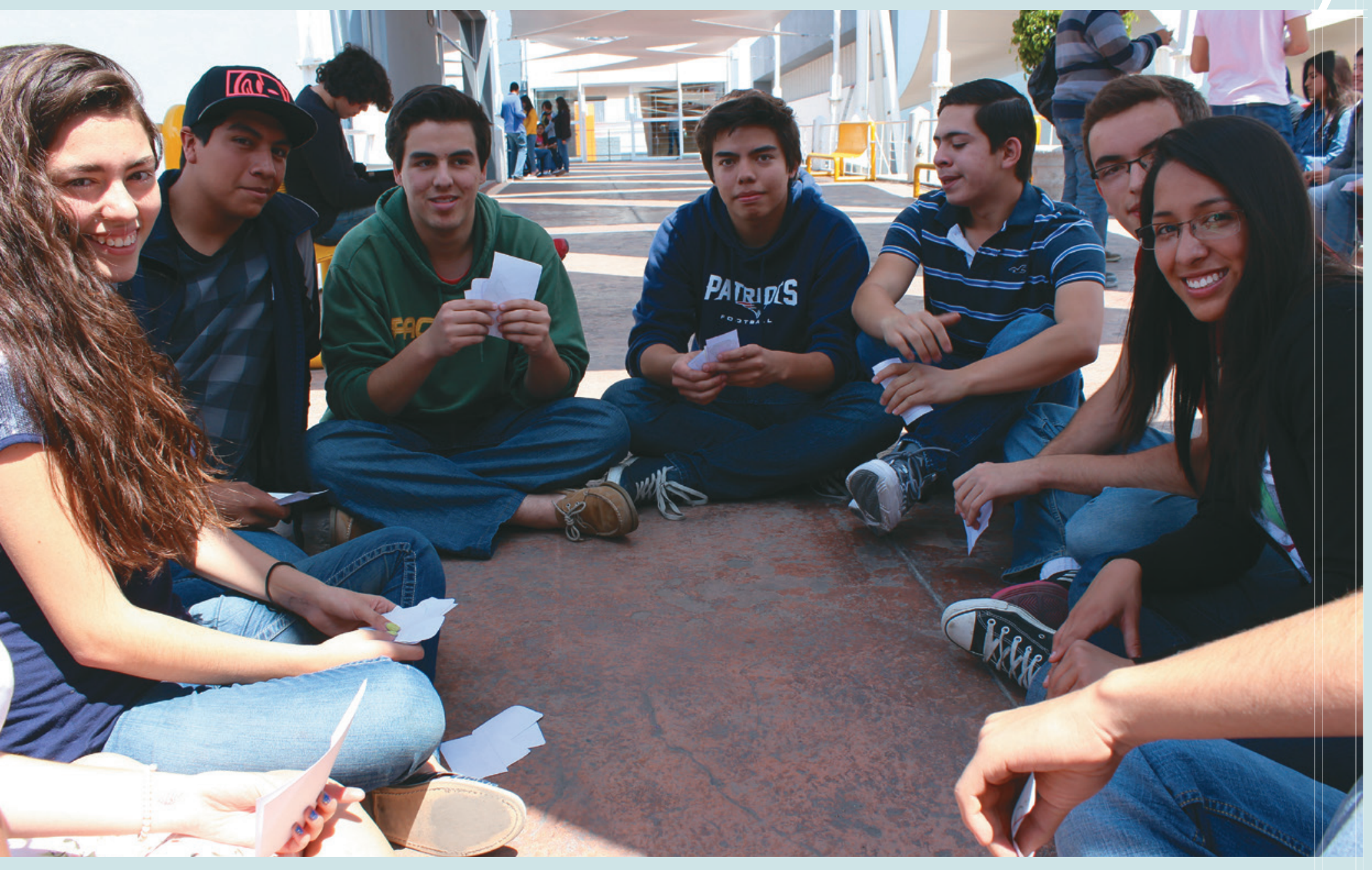

Convergencias: la dignificación de la educación y su estructuración pedagógica

Rodrigo Guerra (2002) considera que toda la filosofía de Karol Wojtyła propone una afirmación de la persona por sí misma, ya que establece que el concepto de dignidad personal, propuesto por el polaco, ofrece i) un marco axiológico para la orientación filosófica, ii) un fundamento ontológico a partir del cual se debe proceder para la construcción de espacios de formación, promoción y, se agrega a esto anterior, iii) un proyecto pedagógico para lograr esta afirmación (Esparza, 2007: caps. 6 y 7).

Sobre la misma línea personalista, teóricos como Víctor García Hoz (1991) han impulsado un ambicioso programa de fundamentación pedagógica y educativa para insistir que todas las prácticas y acciones encaminadas al fortalecimiento y orientación del individuo se deben centrar en el concepto de "persona". García Hoz (1991), al respecto, escribe:

[E]l hecho de colocar la idea de persona como punto de referencia fundamental en la idea de educación confiere una peculiar dignidad al educando y a cualquier elemento humano que intervenga en el proceso educativo. La noción de persona lleva implícita la idea de dignidad por significar «lo más perfecto en una naturaleza» (p. 197). 
Lo que este pedagogo busca poner de relieve es el concepto de "persona" en el proceso entero de la educación, sin importar si se está hablando de una acción encaminada a la consecución de un fin (educación) o del proceso de construcción para su logro (pedagogía), el concepto de persona debe ser el centro en el cual giren todas las acciones de promoción humana. En última instancia, toda práctica pedagógica y educativa debe favorecer que las acciones permitan la afirmación de la persona y su dignidad.

Para estructurar una propuesta pedagógico-personalista, son necesarias tres acciones concretas: una primera tiene que ver con la distinción de los agentes educativos y responde a la pregunta " ¿a quién le corresponde educar?", esta tarea debe ser desarrollada por la Familia, la Escuela, el Arte y la Religión, principalmente. Una segunda acción responde a "¿qué acciones corresponde desarrollar?". Se dirige al análisis y práctica de las distintas tareas educativas: correlacionando cada agente con sus tareas se tiene lo siguiente: a la Escuela le corresponde construir marcos pedagógicos tendientes a la formación de virtudes intelectuales; a la Familia, virtudes morales; al Arte, habilidades técnicas y estéticas; a la Religión, virtudes teologales. Una tercera acción cuestiona “¿cómo se puede educar mejor?”, y tiene como centro de interés la construcción de entornos educativos o "creación de condiciones" para la consecución de los fines específicos que busca el agente (cfr. Orlich et al., 2007: 24-35; Esparza, 2010).

\section{Conclusiones}

Por lo anteriormente analizado, se sostienen dos cosas: primera, que la Educación es el conjunto de acciones que se desarrollan como parte de un proceso de adaptación al entorno; y la Pedagogía, el conjunto de tareas desarrolladas por agentes educativos que tiene como fin la organización sistemática de las conductas para una mejor adaptación del individuo al medio. Segunda, que a pesar de las diferencias conceptuales, ambas acciones confluyen en la promoción de la dignidad de la persona, ya que todo proceso de fomento y formación humana debe tener como centro de reflexión -y construcción- afirmar a la persona por sí misma.

\section{Fuentes de consulta}

Esparza, G. (2007). Sobre la afirmación de la persona sobre sí misma: notas pedagógicas para una teoría pedagógica desde la filosofía de Karol Wojtyła. Tesis inédita: up-Ags.

Esparza, G. (2010). Un modelo didáctico para la enseñanza de la Ética desde la Filosofía de Karol Wojtyła. Tesis inédita: up-Ags.

García, V. (1991). Sobre el concepto de educación personalizada y algunas derivaciones. Madrid: Círculo de Educación Personalizada.

Guerra, R. (2002). Afirmar a la persona por sí misma: el método filosófico de Karol Wojtyła. México: Caparrós.

Orlich, D. Harder, R.; Callahan, R.; Kauchak, D.; Pendergrass, R.; Keogh, A. y Gibson, H. (2007). Técnicas de enseñanza. México: LimUSA.

Wojtyła, K. (1982). Persona y Acción. Madrid: BAC. 